\title{
Electronic Government Research: Topical Directions and Preferences
}

\author{
Hans J. Scholl \\ University of Washington, Seattle, United States \\ jscholl@uw.edu
}

\begin{abstract}
We surveyed the worldwide e-Gov researcher community and collected data on disciplinary backgrounds, topical orientations, and publication preferences from over 200 scholars including more than 80 percent of the most prolific scholars in the domain. The results demonstrate the richness and diversity of electronic government research worldwide. Some topics are more prevalent in some regions than others. The paper presents the results and discusses, which directions the domain may take to further strengthen its growing reputation and recognition.
\end{abstract}

Keywords: Electronic Government Research, Topics, Academic Disciplines.

\section{Introduction}

Electronic Government Research (EGR) has evolved past its infancy [23]. It has been portrayed as a multi-disciplinary and in part interdisciplinary domain of study with a scholarly community of about 900 active individuals worldwide that have published their work in the English language [21, 22]. In terms of volume of EGR publications the core of this community numbers in the 200s. Among those are about 60 highly prolific individuals with double-digit numbers of EGR-related publications forming the innermost group or inner core of the scholarly EGR community [23].

In its early years the study domain had seen quite a few debates about the directions $[1,2,6,11,14,17,28]$, the academic rigor $[12,13,15,16,18,19]$, and the acceptable standards of inquiry [7, 20, 29]. Depending on the rules in their respective home disciplines and sometimes contingent on academic geography, debaters proposed this or that standard as the solely acceptable benchmark for good quality EGR. And, of course, when looking through the lens of any particular discipline, EGR publications from other disciplines that adhered to different standards might not necessarily measure up well against the proposed yardstick. EGR, it became clear, comprised a variety of distinct disciplinary approaches, standards of inquiry, and measures of academic quality. It appears that these differences are now better understood and appreciated, and the plurality of contributions and cross-pollination through employing diverse perspectives are increasingly recognized as a plus rather than a liability of the study domain. 
The volume of EGR publications has dramatically increased from a couple of dozens in 2000 to almost 6,000 peer-reviewed academic contributions in the English language alone by mid 2013, and the annual going rate of peer-reviewed publications, that is, conference papers, journal papers, book chapters, and monographs has now reached almost 500 publications per year [23, 25]. Unlike other fields or study domains, in EGR the worldwide peer-reviewed English-language publications are collected, compiled, and updated semi-annually into a publicly accessible reference library, the Electronic Government Reference Library (EGRL), downloadable from https://catalyst.uw.edu/webq/survey/jscholl/22768. This resource allows for comprehensive bibliometric analyses of the study domain's accumulated body of knowledge at any given time including the major themes and directions in EGR. The EGRL along with the EGOV LIST mailing list along with other sources such as the Linkedin EGOV community with some 5,000 linked members allows for a profiling and assessment of publication productivity in the research community down to the individual scholar's level [22, 23]. When comparatively measuring the volume of papers for various themes and outlets, the EGRL provides a robust and verifiable basis of data for such undertakings.

However, we were also interested in the perceptions and recommendations as well as the personal disciplinary backgrounds and topical interests in the electronic government (EGOV) researcher community. Since the study domain had never been subject to forum or publication outlet rankings, we felt that the growing maturity of the domain warranted such an exercise and conducted a survey, whose results are published elsewhere [26]. Beyond the outlet preferences, we also captured participants' disciplinary backgrounds and major areas of research focus and interests, which we are presenting and discussing in this paper.

The remainder of the paper is organized as follows. We first review the extant, although parsimonious, literature on disciplinary backgrounds and research interests in EGR. We then introduce our methodology and the research question, which is followed by the presentation of the findings and the discussion of the results. We finally conclude and outline the limitations of this study along with future directions of this research avenue.

\section{Short Literature Review}

As indicated above the literature on disciplinary backgrounds and research interests in EGR is anything but exuberant. However, first attempts to identify the quality, characteristics, and directions of EGR were published between 2004 and 2006 and shortly after when the study domain was still in its infancy $[1,4,7,12-14,18,19]$. By the end of 2003, the entire body of EGR knowledge represented about 12.6 percent of the accumulated volume of peer-reviewed EGR at the end of 2012 and amounted to some 700 publications in the English language, 60 percent of which were conference papers, while 35 percent were published in journals and the rest in monographs and edited books [23]. 
EGR reviews in those days tended to employ mono-disciplinary perspectives, for example, of MIS scholarship [12-14] or of Public Administration scholarship [18]; in these assessments, the accepted standards of the respective disciplines were taken for granted and stereotypically applied not only to studies from their originating fields, but also to those from different disciplinary backgrounds causing some irritation and controversy among EGR scholars. However, shortly after this discussion the multidisciplinary nature of EGR was increasingly acknowledged and upheld [4, 7, 21, 23, 24, 26, 29, 30].

Around 2010, towards the end of the first decade of EGR, analyses for single journals (Electronic Government, International Journal of Electronic Government Research, and Transforming Government) appeared, which captured and presented journalrelated geographic, institutional, and academic profiles of the EGR community [8-10]. Based on the EGRL at the same time, more comprehensive profiles, disciplinary backgrounds, and topical mainstays were presented and discussed which also calculated the size of the most prolific core of EGR scholarship (55 individuals) and the extended core (of less prolific) EGR scholars of 225 individuals [22, 23].

Management, organization, and transformation were found the most frequently and extensively studied topics in EGR in the first decade of its existence followed by topics such as digital democracy, electronic services, design studies and tools, policy, governance, and law, infrastructure, integration, and interoperability, information security, and EGR foundations and standard of inquiry [23]. A disciplinary breakdown of the core group of EGR scholars surfaced that Public Administration, Political Science, Management of Information Systems (MIS), Business Administration, Computer Science, and Information Science were the major primary disciplinary training backgrounds of the EGR core group [22].

In summary, EGR, a study domain beyond its infancy [23], has remarkably thrived since the appearance of its initial contributions by the end of the 20th century. The study domain has apparently embraced its multi-disciplinary composition. However, the multitude of evolving topical interests in EGR has not been documented against this backdrop. Neither have the disciplinary nor have geographical differences and preferences in EGR been studied and documented.

\section{Research Questions and Methodology}

\subsection{Research Questions}

The brief review of the literature illustrated a lack of knowledge and documentation regarding the particular research interests and directions in EGR, which scholars in the domain actively pursue or might want to pursue. Since these interests may vary relative to academic discipline, geographic region, or academic standing, the research questions are formulated as follows:

Research Question \#1 (RQ \#1): What are the specific research interests in EGR, and how prevalent are they in the view of EGR scholars? 
Research Question \#2 (RQ \#2): Given the disciplinary backgrounds of EGR scholars, how do the specific research interests vary in EGR, and how prevalent are they with regard to respective disciplinary backgrounds?

Research Question \#3 (RQ \#3): Given the academic standing of EGR scholars, how do the specific research interests vary in EGR, and how prevalent are they with regard to the respective academic standing?

Research Question \#4 (RQ \#4): Given the geographic location of EGR scholars, how do the specific research interests vary in EGR, and how prevalent are they with regard to the respective geographic location?

As has been pointed out before, these research questions could be fully addressed by analyzing the data provided in the EGRL and augmenting these by data available from other public sources. The EGRL would allow for coding and categorizing the entries along the lines of authors' disciplinary backgrounds, academic standings, and geographic locations. Such analysis, reflective of the aforementioned categories, would give a comprehensive account of what actually was published before. However, when directly surveying EGR scholars one can expect to capture more recent or evolving interests in the domain. And, of course, the two approaches are not mutually exclusive. For this study the latter approach was chosen.

\subsection{Sample, Instrument, and Data Collection}

Sample. As mentioned above previous research had estimated the size of the core group of most active and prolific EGR scholars at 55 worldwide, whereas the inner EGR community was found to number in the mid 200's and the extended EGR community at around 700 individuals [22, 23]. The EGOV listserv (egov-list@uw.edu) membership roll as well as the Electronic Government Reference Library (EGRL, version 8.5, end of 2012) provided the main sources of information allowing for the verification of academic background and for survey-participant selection. When this study was conducted the EGOV listserv membership list contained 1,132 entries, 882 of which contained email addresses of persons with a verifiable academic background and an active involvement in EGR. In terms of size, this sample can be estimated as representing a very high percentage of the entire scholarly population in EGR [3].

Instrument. A structured Web-based questionnaire [5] was used containing a total of nine questions with required responses to the first eight questions. Question \#9 provided a non-mandatory entry mechanism for specifying and rating outlets not listed as choices and for providing general feedback. Questions \#1 to \#5 inquired about the academic position, the greater geographical area, the primary and secondary academic disciplines, and the top-three sub-areas of EGR-related interest. For all questions, pre-configured responses could be selected including "other" for choices not listed. Question \#6 to \#8 interrogated about the perceived quality of pre-specified conferences, conference proceedings, and journals. As mentioned before the results of outlet preferences in the EGR community are published separately [26].

Data Collection. Between mid-November and early December of 2012 emails were sent worldwide to the 882 scholars identified as described above, explaining the purpose of the study and inviting recipients to take the survey providing prospective 
participants with an individualized electronic link to the Web-based survey. A week apart, a total of three reminders were sent. The results were electronically recorded and automatically coded in a fashion for immediate use in SPSS. The survey response rate was 23.4 percent with 206 surveys fully completed and valid, which is relatively high and slightly higher than other studies using a similar technique and a three-wave solicitation procedure [27].

\section{$4 \quad$ Findings}

In the following sections the findings are presented one research question at a time. The overall results are presented first (RQ \#1) followed by findings with regard to the disciplinary backgrounds (RQ \#2), academic standings (RQ \#3), and geographic location (RQ \#4).

\subsection{Overall Topical Orientations and Preferences (RQ \#1)}

As mentioned before, participants had been asked to rank their research interests into primary, secondary, and tertiary interests. For distinguishing the rankings, the primary choices were given a weight of 3 , the secondary choices received a weight of 2 , and the tertiary choices were counted with a factor of 1 .

Table 1 shows the weighted "Topics of Interest" for all 206 participants. With 188 (or $15.21 \%$ ) the weighted score for Open Government and Participation was highest by some margin followed by Transformational Government (149/12.06 \%), Services and Information (121/9.79 \%), and Social Media and Social Networking in the Public Sector $(112 / 9.06 \%)$. The scores for this group of four topics, all with triple digits, amount to almost half the total score $(46.12 \%)$ indicating that at the time the survey was conducted these four topical areas were the most popular areas of interest among EGR scholars worldwide.

The second group of EGR areas of interest also comprises four topics with almost identical scores. With a weighted score of less than half the top score Policy, Governance, Ethics, and Law (90/7.28 \%) ranks in fifth place closely followed by Cloud Services, Enterprise Architecture, and Interoperability in the Public Sector and Open Data/Big Data (89/7.20 \% each). The relatively high rank of the latter two topics is not surprising given the rapidly growing proliferation of cloud computing etc. and open/big data in practice, whereas, in fact, the rank for the policy, governance, ethics, and law topics is at least remarkable. As a point of reference, the respective minitrack (a term for topic clusters) under the same title at the Hawaii International Conference on System Sciences (HICSS), despite being one of the oldest EGOV minitracks at that cluster conference, has never received a remarkably high number of submissions, although the quality of papers submitted to that particular minitrack has consistently been outstanding. In this "runner-up" group of topical interest another traditional topic is found, that is, IT Service Management in the Public Sector (87/7.04 \%). The four topics have a combined group score of 355, which represents $28.7 \%$ of the total score. So, the top-two topical areas account for almost exactly three fourths of EGR topics. 
Table 1. Topical Areas of Interest in EGR

\begin{tabular}{|c|c|c|c|}
\hline $\begin{array}{c}\text { All Participants (Weighted Topics } \\
\text { of Interest) }\end{array}$ & $\begin{array}{l}\text { Weighted } \\
\text { Score }\end{array}$ & Percent & $\begin{array}{c}\text { Cumulative } \\
\text { Percent }\end{array}$ \\
\hline Open government and participation & 188 & $15.21 \%$ & $15.21 \%$ \\
\hline Transformational government & 149 & $12.06 \%$ & $27.27 \%$ \\
\hline Services and information & 121 & $9.79 \%$ & $37.06 \%$ \\
\hline $\begin{array}{l}\text { Social media and social networking in the } \\
\text { public sector }\end{array}$ & 112 & $9.06 \%$ & $46.12 \%$ \\
\hline Policy, governance, ethics, and law & 90 & $7.28 \%$ & $53.40 \%$ \\
\hline $\begin{array}{l}\text { Cloud services, enterprise architecture, } \\
\text { and interoperability in the public sector }\end{array}$ & 89 & $7.20 \%$ & $60.60 \%$ \\
\hline Open data / big data & 89 & $7.20 \%$ & $67.80 \%$ \\
\hline $\begin{array}{l}\text { IT Service Management in the public } \\
\text { sector }\end{array}$ & 87 & $7.04 \%$ & $74.84 \%$ \\
\hline Digital divide/s in the public sector & 46 & $3.72 \%$ & $78.56 \%$ \\
\hline $\begin{array}{l}\text { Smart cities, smart grids, and smart } \\
\text { government }\end{array}$ & 44 & $3.56 \%$ & $82.12 \%$ \\
\hline Electronic campaigning and elections & 40 & $3.24 \%$ & $85.36 \%$ \\
\hline $\begin{array}{l}\text { EGOV education, training, and } \\
\text { professionalization }\end{array}$ & 39 & $3.16 \%$ & $88.51 \%$ \\
\hline $\begin{array}{l}\text { ICT-enabled crisis, disaster, and } \\
\text { catastrophe management }\end{array}$ & 31 & $2.51 \%$ & $91.02 \%$ \\
\hline Other & 24 & $1.94 \%$ & $92.96 \%$ \\
\hline Infrastructure security & 20 & $1.62 \%$ & $94.58 \%$ \\
\hline Electronic procurement and logistics & 17 & $1.38 \%$ & $95.95 \%$ \\
\hline Cyber warfare & 16 & $1.29 \%$ & $97.25 \%$ \\
\hline $\begin{array}{l}\text { Geographical planning / geographical } \\
\text { information system in the public sector }\end{array}$ & 15 & $1.21 \%$ & $98.46 \%$ \\
\hline $\begin{array}{l}\text { Electronic record management and } \\
\text { archiving }\end{array}$ & 13 & $1.05 \%$ & $99.51 \%$ \\
\hline $\begin{array}{l}\text { Insider threats modeling, detection, and } \\
\text { mitigation }\end{array}$ & 6 & $0.49 \%$ & $100.00 \%$ \\
\hline Total Score & 1236 & $100.00 \%$ & \\
\hline
\end{tabular}

The remaining two groups of topical interests combine both traditional specialty topics and novel topics, which might have the potential of commanding wider interest in the future. The third group of EGR areas of interest encompasses five topics: Digital Divide/s in the Public Sector (46/3.72\%), Smart City/Smart Grids /Smart Government (44/ $3.56 \%)$, Electronic Campaigning and Elections (40/3.24 \%), EGOV Education, Training, and Professionalization (39/3.16\%), and ICT-enabled Crisis, Disaster, and Catastrophe Management (31/2.51\%). While the digital divide/s topic has been studied for more than a decade, the other four topics are relatively novel. Their combined score equals 200 representing $16.2 \%$ of the total score.

The last group of topical areas includes Infrastructure Security (20/1.62 \%), Electronic Procurement and Logistics (17/1.38 \%), Cyber Warfare (26/1.29 \%), GIS in the Public Sector (15/1.21 \%), Electronic Record Management and Archiving (13/1.05 $\%)$, and Insider Threats Modeling, Detection, and Mitigation (6/0.49 \%) among other topics $(24 / 1.94 \%)$ altogether. This last group has a combined score of 111 , or $8.9 \%$ of 
the total score. Interestingly, the two topics of infrastructure security and insider threat modeling/detection/and mitigation attract a relatively high number of submissions at HICSS indicating that these special areas have clustered around this venue.

When looking at the rankings of primary, secondary, and tertiary areas of interest, it is instructive to see that the topic of open government and participation tops both lists, primary and secondary topics of interest, and is second to transforming government on the list of tertiary interests. Also, the area of services and information is among the top four in all three lists. Interestingly, the areas of electronic record management and insider threat modeling, detection, and mitigation are either in the bottom four areas or not on the list at all. Further, GIS systems in the public sector is listed last, or last but one respectively, on the lists of primary and secondary interests. The low scores indicate that these topics are of special interest and only appeal to a small sub-group of the EGR community.

In summary, the lion share of topical interests in EGR is represented by eight topics with open government and participation attracting almost twice as much interest as the fourth (and last) topical group combined and almost as much as the third group altogether. Also in the top group of four topics were transformational government, services and information, and social media and social networking in the public sector.

\subsection{Topical Orientations Relative to Disciplinary Backgrounds (RQ \#2)}

In this part of the analysis, we are distinguishing four major groups of disciplinary backgrounds, that is, Public Administration and Political Science $\left(n_{p}=48\right)$, Management of Information Systems and Computer Science $\left(\mathrm{n}_{\mathrm{mc}}=106\right)$, Information Science $\left(\mathrm{n}_{\mathrm{i}}=15\right)$, and other disciplinary backgrounds $\left(\mathrm{n}_{\mathrm{od}}=37\right)$. While so doing, it is acknowledged that Public Administration research and Political Science are distinct disciplines as are MIS and computer science. These four distinct disciplines were only clustered with regard to their technology affinity, or non-affinity, respectively. Public Administration and Political Science it was assumed were less technology-affine than MIS and Computer Science. It is explicitly not suggested that differences between these traditional disciplines are minor or negligible. Only with regard to their relative distance when studying technology-related phenomena they appeared to be clusterable.

Unsurprisingly, scholars in the cluster of Public Administration and Political Science ranked the four areas of (a) open government and participation, (b) transformational government, (c) policy, governance, ethics, and law as well as (d) social media and social networking in the public sector highest accounting for almost 55 percent of the weighted score total. In the second group of topical preferences (d) IT service management in the public sector, (e) services and information, and (f) electronic campaigning and elections were most favored representing another 23.7 percent of the total weighted score total. So, the top seven areas of interests accounted for 78.67 percent of topical interests in EGR from a public administration or political 
science scholar's perspective. However, maybe even more interesting was to find that some topical areas were absent from the lists of interest of public administration and political science scholars: (1) infrastructure security, (2) electronic procurement, (3) cyber warfare, (4) electronic record management, and (5) insider threat detection, modeling, and mitigation.

With 51.5 percent of survey respondents MIS and Computer Science represented the largest cluster $\left(\mathrm{n}_{\mathrm{mc}}=106\right)$ in the sample. Scholars in this cluster had the widest range of topical interests (20+); however, despite the large number of topical interests in this part of the scholarly EGR community, seven topics covered the vast majority of interests. The top two areas were (a) open government and participation and (b) transformational government. These were followed by (c) cloud services, enterprise architecture, and interoperability in the public sector as well as (d) services and information, (e) social media and networking, (f) open data/big data, and (g) IT service management in the public sector, which altogether accounted for 69.5 percent of the weighted score total in that cluster.

Although a relatively small group $\left(7.3 \%\right.$, or $\left.\mathrm{n}_{\mathrm{i}}=15\right)$, Information Science represented a distinct scholarship among survey respondents. Clustering information science with one of the former two groups was seen as inadequate since the field maintains a middle ground in terms of technology affinity; it is neither highly technology-affine, nor the opposite. And, in fact, some remarkable differences surfaced in the preferences of this field's respondents. They ranked highest (a) services and information highest, followed by (b) policy, governance, ethics, and law, and (c) cloud services, enterprise architecture, and interoperability in the public sector. Also, the topics of (d) open government and participation, and (e) ICT-enabled crisis, disaster, and catastrophe management, all of which combined to over half of the weighted total score of topical interests of information science scholars in EGR. Remarkably, the information scientists had little interest in open data/big data, transformational government, and social media and social networking in the public sector.

EGR scholars from all other disciplines $\left(\mathrm{n}_{\mathrm{od}}=37\right)$, representing 17.98 percent of all respondents, had the following top-five areas of interests: (a) open government and participation, (2) transformational government, (3) open data / big data, (4) social media and social networking in the public sector, and (5) services and information, which amounted to almost 56 percent of the weighted total score of interests. Interestingly, EGR scholars from other disciplines than the aforementioned had no interest in insider threat modeling, detection, and mitigation, infrastructure security, ICT-enabled crisis, disaster, and catastrophe management, and digital divide/s.

In summary, unsurprisingly depending on disciplinary backgrounds the topics of interest vary, and so do their rankings. However, the topic of open government and participation appears in the top five interests of all disciplinary backgrounds, and transformational government along with services and information make the top five in three of four disciplinary clusters or fields. 


\subsection{Topical Orientations Relative to Academic Standings (RQ \#3)}

It was assumed that the topical interests of EGR scholars might also vary with their academic standing. By and large, academic standing can be distinguished along the lines of tenure track and non-tenure track. Scholars on tenure track can either be senior, that is, tenured in the ranks of associate or full professor, or junior, that is, untenured at the ranks of assistant professor. Non-tenure track scholars encompass research professorships, and post-doc positions among other including non-tenured teaching positions. Three clusters of respondents were formed accordingly with tenured faculty $\left(\mathrm{n}_{\mathrm{ten}}=89\right)$, untenured (tenure-track) faculty $\left(\mathrm{n}_{\mathrm{unt}}=28\right)$, and other EGR scholars $\left(\mathrm{n}_{\mathrm{os}}=89\right)$. Coincidently, the two respondent groups of senior faculty and other scholars were equal in size.

Senior faculty were mostly interested in (a) open government and participation, (b) transformational government, (c) social media and social networking in the public sector, (d) services and information, and (e) IT service management in the public sector (combining to 54.12 percent of the weighted score total). Of least interest to this group were cyber warfare, electronic procurement and logistics, infrastructure security, and insider threat modeling, detection, and mitigation.

Junior faculty shared the top four topics with senior faculty, (a) open government and participation and (b) social media and social networking in the public sector, (c) transformational government, and (d) services and information, although in slightly different order. As fifth-ranked topic junior faculty was interested in (e) electronic campaigning and elections. The top five topics accounted for 55.36 percent of the weighted score total. This group was least interested in cyber warfare, insider threatrelated topics, and GIS.

Non-tenure track EGR scholars also ranked (a) open government and participation and (b) transformational government on top, followed by (c) services and information, (d) cloud services, enterprise architecture, an interoperability, and (e) open data/big data comprising 55.81 percent of the weighted score total. The bottom ranks of interest encompassed cyber warfare, electronic procurement and logistics, GIS, and insider threats-related topics.

In summary, tenure-track faculty shared the top four topics, and three topics, ranked among the top five topics, were found across all academic standings. Insiderthreat-related topics were found special-interest topics along with GIS-related topics.

\subsection{Topical Orientations Relative to Geographic Location (RQ \#4)}

Geographic locations of EGR scholars had been covered marginally in previous investigations, when topical orientations were considered. In this study, the largest group of respondents came from Europe and the UK $\left(\mathrm{n}_{\mathrm{eu}}=113\right.$, or $\left.54.9 \%\right)$ followed by respondents from North America $\left(\mathrm{n}_{\mathrm{na}}=51\right.$, or $\left.24.8 \%\right)$ and from other world regions $\left(\mathrm{n}_{\mathrm{or}}=42\right.$, or $\left.20.3 \%\right)$.

European and UK EGR scholars had a strong preference for (a) open government and participation, (b) transformational government (c) services and information, (d) cloud services etc., and (e) IT service management together accounting for 59 percent 
of the weighted score total, whereas GIS-related topics, crisis-related topics, and insider threat-related topics were at the bottom of the ranking.

North American scholars in contrast, while likewise being interested in (a) open government and participation, ranked (b) social media and social networking in the public sector, (c) open data/big data, (d) policy, governance, ethics, and law, (e1) services and information and (e2) transformational government as their highestscoring topics of interest. These six topics accounted for 58.6 percent of the weighted score total. It is noteworthy that this group was least interested in the topics of EGOV education, electronic record management and archiving, and insider threats-related topics.

The other geographic areas ranked fewer topics of interest than the other two: the top-five topics were (a) transformational government, (b) open government and participation, (c) social media etc., (d) IT service management, and (e) electronic campaigning and elections representing 52.8 percent of the weighted score total. At the bottom of the list of topics of interests (with no mention) were cyber warfare, electronic record management, and insider threats-related topics.

In summary, while open government and participation along with transformational government were among the top topics of interest also in the geographical breakdown, greater topical variety emerged in the top five topics of interests depending on geographical location.

\section{Discussion, Future Research, and Concluding Remarks}

The study's object has been to uncover the breakdown of topical interests in EGR. Once a better understanding of the breakdown of topical emphases and of the variety of EGR is established in detail, an assessment of the direction of the EGR study domain can be undertaken. The findings here are based on a survey of the worldwide EGR scholar population. The response rate was relatively high $(23.4 \%)$ overall and exceptionally high among the most prolific EGR scholars (81\%). So, some confidence in the robustness of the results appears warranted. However, with 54.9 percent responses from Europe and the UK, the overall results presented here might possibly be skewed towards European/UK preferences. In the geographical analysis (RQ \#4) evidence was given that the European/UK topical preferences were different in part when compared with those from other parts of the world.

That notwithstanding and regardless of disciplines, academic standings, and geographic provenance of EGR scholars, the topics of open government and participation and transformational government were the most frequently mentioned topics of interest in EGR. The former topic emerged under this label only a few years ago and since has rapidly moved to the top of the list, so some caution with regard to its long-term popularity might be in order. Future studies will find out how sustainable the topic has proven to be. When compared to earlier studies that listed the topics of (a) management organization, and transformation, (b) digital democracy, (c) electronic services, (d) and policy-related topics as prevalent [23], it appears that these topics have been continued under slightly different denominations and 
combinations. In other words, these topics have maintained a high amount of scholarly interest over the years. Other topics such as (e) design studies and tools [23] might have been absorbed at least in part into what is now labeled IT service management. Compared with the previous study, the broadly attractive novel topics of interest in the top two groups are open government and transparency, social mediarelated topics, cloud services-related topics, and open data/big data. Of more special interest were novel topics such as ICT-enabled disaster management, cyber warfare, and insider threats-related topics, which had never been mentioned before. At the same time traditional special interest topics such as GIS-related topics and electronic record management have not gained stronger traction. However, the fact that a topic is not ranked high in the table does not mean that it is uninteresting or fading, but rather that only fewer EGR scholars are inclined to engage in it.

In the absence of a comprehensive bibliometric analysis of the EGRL no more detailed trends on topical preferences of EGR scholars from the past to the present can be given at this point. Still, while bibliometric analyses of already published work present objective data on topical preferences and interests in the past as can be found in the EGRL, a survey provides a snapshot of most recent interests including EGR scholars' intention to engage in future studies in a specific area. In other words, this study might also help identify emerging topics, which attracted higher attention and heightened interest at the time of taking the survey. A repeat of this study will be able to show how topical interests have changed over the years also from scholars' perspective. In future research, it is planned to analyze and systematically compare survey-generated data with bibliometric data in more detail. For conducting such research the EGRL will serve as a comprehensive resource.

In summary, as a multi-disciplinary domain of study, EGR has always covered a wide variety of areas of study, many of which are of great interest across disciplines, academic standings, and geographical areas. This is even more profoundly shown through this study. EGR appears to have emerged as an academically pluralist and global undertaking, which continuously generates a rich and diverse research agenda fueled by contributions from quite a number of fields, and the scholarly community is seemingly both willing and capable of embracing rather quickly novel phenomena from various angles of view.

\section{References}

1. Andersen, K.V., Henriksen, H.Z.: The First Leg of E-Government Research: Domains and Application Areas 1998-2003. International Journal of Electronic Government Research 1(4), 26-44 (2005)

2. Bicking, M.: Roadmapping future e-Government research: Government's role and responsibilities in the virtual world. In: Li, Y., Duan, Z., Yan, L., Li, H., Yang, X. (eds.) 9th IFIP International Conference on e-Business, e-Services, and e-Society (I3E 2007), Integration and Innovation Orient to E-Society Volume 2. IFIP, vol. 252, pp. 469-480. Springer, Boston (2007)

3. Cochran, W.G.: Sampling techniques. John Wiley \& Sons (2007)

4. Cushing, J., Pardo, T.: Guest Editors' Introduction: Research in the Digital Government Realm. Computer 38(12), 26-32 (2005) 
5. Daley, E.M., McDermott, R.J., McCormack Brown, K.R., Kittleson, M.J.: Conducting web-based survey research: a lesson in internet designs. American Journal of Health Behavior 27(2), 116-124 (2003)

6. Dawes, S.S., Gregg, V., Agouris, P.: Digital government research. Social Science Computer Review 22(1), 5 (2004)

7. Delcambre, L., Giuliano, G.: Digital government research in academia. Computer 38(12), 33-39 (2005)

8. Dwivedi, Y.K.: An analysis of e-Government research published in Transforming Government: People, Process and Policy (TGPPP?). Transforming Government: People, Process and Policy 3(1), 7-15 (2009)

9. Dwivedi, Y.K., Singh, M., Williams, M.D.: Developing a demographic profile of scholarly community contributing to the Electronic Government, An International Journal. Electronic Government, An International Journal 8(2/3), 259-270 (2011)

10. Dwivedi, Y.K., Weerakkody, V.: A Profile of Scholarly Community Contributing to the International Journal of Electronic Government Research. International Journal of Electronic Government Research 6(4), 1-11 (2010)

11. Flak, L.S., Sein, M.K., Sæbø, Ø.: Towards a Cumulative Tradition in E-Government Research: Going Beyond the Gs and Cs. In: Wimmer, M.A., Scholl, J., Grönlund, Å. (eds.) EGOV. LNCS, vol. 4656, pp. 13-22. Springer, Heidelberg (2007)

12. Grönlund, Å.: State of the Art in e-Gov Research - A Survey. In: Traunmüller, R. (ed.) EGOV 2004. LNCS, vol. 3183, pp. 178-185. Springer, Heidelberg (2004)

13. Grönlund, Å., Andersson, A.: e-Gov Research Quality Improvements Since 2003: More Rigor, but Research (Perhaps) Redefined. In: Wimmer, M.A., Scholl, H.J., Grönlund, Å., Andersen, K.V. (eds.) EGOV 2006. LNCS, vol. 4084, pp. 1-12. Springer, Heidelberg (2006)

14. Grönlund, Å., Horan, T.A.: Introducing e-Gov: History, Definitions, and Issues. Communications of the Association for Information Systems 15(39), 713-729 (2005)

15. Heeks, R., Bailur, S.: Analyzing e-government research: Perspectives, philosophies, theories, methods, and practice. Government Information Quarterly 24(2), 243-265 (2007)

16. Holden, S.H., Norris, D.F., Fletcher, P.D.: Electronic Government at the Grass Roots: Contemporary Evidence and Future Trends. In: 36th Hawaii International Conference on System Sciences (HICSS-36), vol. 5, p. 134c (131-138). Computer Societry Press, Island of Hawaii (2003)

17. Muñoz, L.A., Bolívar, M.P.R., Hernánde, A.M.L.: Analyzing the e-Government Research (2000-2009): State of the art, Contextualization and Research Opportunities. In: Proceedings of the 4th International Conference on Methodologies, Technologies and Tools enabling e-Government (MeTTeG 2010), Olten, Switzerland, July 1-2, pp. 69-84 (2010)

18. Norris, D.F.: E-Government at the American Grassroots: Future Trajectory. In: 38th Hawaii International Conference on System Sciences (HICSS-38), p. 125b (121-128). Computer Societry Press, Island of Hawaii (2005)

19. Scholl, H.J.: Is E-Government Research a Flash in the Pan or Here for the Long Shot? In: Wimmer, M.A., Scholl, H.J., Grönlund, Å., Andersen, K.V. (eds.) EGOV 2006. LNCS, vol. 4084, pp. 13-24. Springer, Heidelberg (2006)

20. Scholl, H.J.: Central research questions in e-government, or which trajectory should the study domain take? Transforming Government: People, Process and Policy 1(1), 67-88 (2007) 
21. Scholl, H.J.: Discipline or interdisciplinary study domain? Challenges and Promises in Electronic Government Research. In: Chen, H., Brandt, L., Gregg, V., Traunmüller, R., Dawes, S., Hovy, E., Macintosh, A., Larson, C.A. (eds.) Digital Government: EGovernment Research, Case Studies, and Implementation, pp. 19-40. Springer, New York (2007)

22. Scholl, H.J.: Profiling the EG Research Community and Its Core. In: Wimmer, M.A., Scholl, H.J., Janssen, M., Traunmüller, R. (eds.) EGOV 2009. LNCS, vol. 5693, pp. 1-12. Springer, Heidelberg (2009)

23. Scholl, H.J.: Electronic Government: A study Domain Past Its Infancy. In: Scholl, H.J. (ed.) E-Government: Information, Technology, and Transformation, vol. 17, pp. 11-32. M.E. Sharpe, Armonk (2010)

24. Scholl, H.J.: Electronic Government: Introduction to the Domain. In: Scholl, H.J. (ed.) EGovernment: Information, Technology, and Transformation, vol. 17, pp. 3-10. M.E. Sharpe, Armonk (2010)

25. Scholl, H.J. (ed.) Record Year for E-Government-Related Productivity, vol. 2013. University of Washington, Seattle (2012)

26. Scholl, H.J., Dwivedi, Y.K.: Forums for Electronic Government Scholars: Insights from a 2012/2013 Study (forthcoming, 2013)

27. Sills, S.J., Song, C.: Innovations in Survey Research: An Application of Web-Based Surveys. Social Science Computer Review 20(1), 22-30 (2002)

28. Wimmer, M.A., Codagnone, C., Ma, X.: Developing an E-Government Research Roadmap: Method and Example from E-GovRTD2020. In: Wimmer, M.A., Scholl, J., Grönlund, Å. (eds.) EGOV. LNCS, vol. 4656, pp. 1-12. Springer, Heidelberg (2007)

29. Yildiz, M.: E-government research: Reviewing the literature, limitations, and ways forward. Government Information Quarterly 24(3), 646-665 (2007)

30. Yıldı, M., Saylam, A.: E-government discourses: An inductive analysis. Government Information Quarterly 30(2), 141-153 (2013) 